\title{
Trait Mindfulness as a Protective Factor in Connections between Psychological Issues and Facebook Addiction among Turkish University Students
}

\author{
Mustafa Eşkisu ${ }^{1}$, Zekeriya Çam² ${ }^{(i)}$, Sedat Gelibolu² ${ }^{(i)}$, Kyler Ray Rasmussen ${ }^{(i D}$ \\ ${ }^{1}$ Erzincan Binali Yıldırım University, Faculty of Education, Erzincan, Turkey \\ ${ }^{2}$ Muş Alparslan University, Faculty of Education, Muş, Turkey \\ ${ }^{3}$ Government of Alberta, Community and Social Services, Alberta, Canada
}

\begin{abstract}
Facebook addiction is a growing issue that has increasingly attracted the attention of clinicians and researchers in a variety of countries and cultures. Relying on the Cognitive-Behavioral Model for Pathological Internet Use, and in a sample of Turkish undergraduates, we investigate whether mindfulness might account for how self-esteem and psychological problems (depression, anxiety, and stress) connect to Facebook addiction. A total of 298 college students completed measures of Facebook addiction, self-esteem, mindfulness and psychological problems, which we analyzed using path analysis, testing various models of how Facebook addiction might be predicted by these factors. We found that Facebook addiction was positively associated with psychological problems and negatively associated with self-esteem and mindfulness, with mindfulness fully accounting for the association between psychological problems, self-esteem and Facebook addiction. These results support the role of mindfulness in the prevention of Facebook addiction and the treatment of addicted individuals. This study also helps clarify previous research connecting mindfulness to Internet addiction, and extends those findings cross-culturally to a Turkish context.
\end{abstract}

Key words: mindfulness, Facebook addiction, depression, anxiety, stress

\section{Introduction}

Social media has become ubiquitous and routine - Facebook is the third most visited website after Google and YouTube (Alexa, 2018) with 1.45 billion daily active users (Facebook ${ }^{\circ}$, 2018). Fifty-three percent of the total popu- lation of Turkey uses Facebook, spending an average of 2 hours and 48 minutes on social media per day; $25 \%$ of the 51 million active Facebook users are between the ages of 18 24 (We Are Social \& Hootsuite, 2018).

Facebook is a social and psychological tool where social relationships are built, one's personality is reflected and deficiencies are

Correspondence concerning this article should be addressed to Mustafa Eşkisu, Ph.D, Department of Educational Sciences, Faculty of Education, Erzincan Binali Yıldırım University, 24100, Erzincan, Turkey. E-mail: meskisu@gmail.com

Received September 23,2019 
compensated (Eşkisu, Hoşoğlu, \& Rasmussen, 2017). Although Facebook use has clear benefits (e.g., enhancing socialization and learning opportunities; (O'Keeffe \& Clarke-Pearson, 2011), there is also the potential for addiction and problematic patterns of use (Andreassen \& Pallesen, 2014; O'Keeffe \& Clarke-Pearson, 2011). Facebook addiction is a subtype of Internet addiction and social media addiction, which involves "being overly concerned about social media, driven by an uncontrollable motivation to log on to or use social media, and devoting so much time and effort to social media that it impairs other important life areas" (Andreassen \& Pallesen, 2014; Koc \& Gulyagci, 2013). While the prevalence of Internet addiction among college students in Turkey ranges from $0.7 \%$ to $8.75 \%$, the prevalence of excessive Internet use exceeds 10\% (Błachnio et al., 2019; Ceyhan, Boysan, \& Kadak, 2019), and 6.1\% meet criteria for addiction to social media (Kircaburun \& Griffiths, 2018). Similarly, $22.6 \%$ of Turkish college students exhibit risk for Facebook addiction (BalCl \& Gölcü, 2013).

Facebook addiction is predicted by a number of negative mental states, including low self-esteem (Herrera, Pacheco, Palomar, \& Zavala, 2010), depression (Błachnio, Przepiórka, \& Pantic, 2015; Herrera et al., 2010), low subjective well-being (Satici \& Uysal, 2015), and high anxiety (Koc \& Gulyagci, 2013; McCord, Rodebaugh, \& Levinson, 2014). Moreover, a significant number of studies in the literature demonstrate that excessive use of Internet or Facebook are often comorbid with other psychological disorders such as depressive disorder, hostility and social anxiety disorder (Błachnio et al., 2015; Ko, Yen, Yen, Chen, \& Chen, 2012; Tang \& Koh, 2017). Although some studies have shown that psychological deficiencies may lead individuals to compensate for these deficiencies via social media (Eşkisu et al., 2017; Kanat-Maymon, Almog,
Cohen, \& Amichai-Hamburger, 2018), there is a gap in the literature on the studies that explain the mechanisms accounting for the co-existence of psychological disorders and Internet/Facebook addiction. This study suggests that one of the factors explaining this mechanism may be mindfulness.

Facebook addiction is negatively associated with mindfulness (Sriwilai \& Charoensukmongkol, 2016) - individuals with higher levels of mindfulness have lower levels of problematic internet use (Gámez-Guadix \& Calvete, 2016; Iskender \& Akin, 2011; Şehidoğlu, 2014). As higher levels of mindfulness are also associated with decreased depression, anxiety, and stress, as well as higher self-esteem (Bluth \& Blanton, 2014; Pepping, O'Donovan, \& Davis, 2013; Thompson \& Waltz, 2008), there is the potential for mindfulness to play an important role in the connection between psychological problems and Facebook addiction. Our study contributes to this existing literature by using path analysis to test a number of different models of how mindfulness and psychological issues connect to predict Facebook addiction, helping to clarify whether the role of mindfulness is direct or indirect. We also make use of a sample of Turkish undergraduates, helping to extend previous findings cross-culturally and further establishing mindfulness as a useful avenue for understanding and preventing Facebook addiction.

Turkey has much in common with Western countries, but there are some important differences that justify an investigation into Turkish Facebook use. Cross-national comparisons of Facebook addiction and associated risk factors, which included Turkish participants, have shown substantial differences from country to country (Błachnio et al., 2016; Błachnio et al., 2019; Błachnio, Przepiorka, Senol-Durak, Durak, \& Sherstyuk, 2017). Facebook and computers more generally have been incorporated into Turkish culture more recently 
than they have in the U.S., which means that Turkish university students may experience increased computer anxiety compared to students in other countries (Tekinarslan, 2008). Such anxiety could, for instance, influence those with low self-esteem to use Facebook more often as a means of social compensation (Lee \& Robbins, 1998). Turkish culture also tends to be more collectivist than those in the West (Göregenli, 1997), and those with a collectivist orientation exhibit different patterns of online social networking than those with an individualistic orientation (Qiu, Lin, \& Leung, 2013). These factors, in conjunction with the prevalence of Facebook addiction in Turkey, necessitate in-depth exploration of the mechanisms underlying Facebook addiction within that cultural context.

\section{Psychological Symptoms, Self-Esteem and Facebook Addiction}

We apply the Cognitive-Behavioral Model for Pathological Internet Use (Caplan, 2010; Davis, 2001) to explain the connection between psychological issues and Facebook addiction. The model consists of four main components. Some psychological issues (depression, anxiety, low self-esteem, etc.) predispose individuals to prefer online social interaction (the first component). The preference for online social interaction may lead to use of the Internet to regulate mood (the second component). Both the preference for online interaction and the use of the Internet for mood regulation reinforce deficient self-regulation of Internet use (the third component) that consists of cognitive preoccupation and compulsive Internet use. Finally, deficient self-regulation of Internet use leads to the development of negative outcomes (the fourth component) such as health and social problems. Studies testing these ideas have found that using Facebook to regulate mood predicts decreases in self-reg- ulation of social media use (Lee, Cheung, \& Thadani, 2012). A recent review on Facebook addiction also shows that individuals with depression, anxiety and loneliness tend to use Facebook for social support, to pass time and to escape from a negative mood (Ryan, Chester, Reece, \& Xenos, 2014), further supporting the Cognitive-Behavioral Model. The theory suggests that psychological disorders are not themselves the proximal causes of Internet addiction. Instead, these issues more distally connect to addictive behaviors through mediating psychological processes.

Social Compensation Theory (Tice, 1993), which states that people with low self-esteem may compensate by expanding their social environment, can explain the relationship between self-esteem and Facebook addiction. Previous studies suggest that those with low self-esteem are more likely than those with high self-esteem to use Facebook to boost self-esteem (Eşkisu et al., 2017; Lee, Moore, Park, \& Park, 2012). Furthermore, higher levels of contingent self-worth (i.e., where self-worth is contingent on other's acceptance) are related to more excessive and maladaptive Facebook use (Kanat-Maymon et al., 2018), suggesting that Facebook addiction may be encouraged by a desire for acceptance by others. Overall, these theories lead us to make the following predictions:

H1a: Psychological problems will be positively related to Facebook addiction.

$H 1 b$ : Self-esteem will be negatively related to Facebook addiction.

\section{The Role of Mindfulness}

Mindfulness can be defined as "paying attention in a particular way: on purpose, in the present moment, and nonjudgmentally" (Kabat-Zinn, 2009, p. 4). Bishop et al. (2004) conceptualized mindfulness as having two components. The first component is self-reg- 
ulation of attention, which means bringing awareness of immediate experience - observing thoughts, feelings and sensations - by regulating the focus of attention. The second component includes adopting an orientation toward one's experience in the present moment, qualified by curiosity, acceptance and openness. There are different approaches regarding the conceptualization of mindfulness. It has been conceptualized as a state experienced in meditation (Lau et al., 2006) but also as a stable trait presenting one's predisposition to be mindful in life (Brown \& Ryan, 2003). However, previous studies found that mindfulness based interventions increase trait mindfulness and that this increase in trait mindfulness may help to mitigate psychological problems (Bögels, Hoogstad, van Dun, de Schutter, \& Restifo, 2008)

Several correlational studies have examined the role of trait mindfulness in psychological problems especially in depression, anxiety and stress (Ciesla, Reilly, Dickson, Emanuel, \& Updegraff, 2012; Royuela-Colomer \& Calvete, 2016). Interventions designed in experimental studies to increase trait mindfulness may effectively reduce or prevent psychological problems in children and adolescents (Bögels et al., 2008; Raes, Griffith, Van der Gucht, \& Williams, 2014; Van der Oord, Bögels, \& Peijnenburg, 2012). Additionally, previous correlational research has also connected mindfulness to various self-regulation issues - higher levels of trait mindfulness are associated with decreased substance-abuse (Bowen \& Enkema, 2014), pathological gambling (Riley, 2014), exercise addiction (Shonin, Van Gordon, \& Griffiths, 2014), as well as problematic Internet use (Gámez-Guadix \& Calvete, 2016).

Although the larger literature described above demonstrates that a number of negative mental states, including depression, anxiety, and low self-esteem, predict Face- book addiction, the underlying mechanism of this relationship is unclear. Considering the relation of trait mindfulness with psychological problems (Royuela-Colomer \& Calvete, 2016) and addiction (Calvete, Gámez-Guadix, \& Cortazar, 2017), the present research suggests that mindfulness may have an explanatory and protective role in the formation of this mechanism. However, we do not know whether mindfulness is directly related to addictive behaviors, or whether these associations can be attributed to incidental connections between mindfulness and depression, anxiety, and other emotional problems.

Using the Cognitive-Behavioral Model, which suggests that psychological problems are connected to Facebook addiction through some psychological process, the present study hypothesized that mindfulness is directly connected to addiction. If so, psychological problems and self-esteem could indirectly relate to Facebook addiction through mindfulness, with mindfulness serving to protect against addictive behavior independent of its connection to other psychological problems. In our analysis, we call this model the "indirect model".

The role of mindfulness could function through several different plausible mechanisms. For instance, mindfulness may serve to bolster the same intervening factors suggested by the Cognitive-Behavioral Model. High levels of trait mindfulness entails being less judgmental of oneself and one's social behaviors, which is associated with more effective interpersonal skills (Beauchemin, Hutchins, \& Patterson, 2008; Dekeyser, Raes, Leijssen, Leysen, \& Dewulf, 2008), with poor interpersonal skills proposed as antecedents of Internet addiction (Caplan, 2010). Mindful awareness (Gámez-Guadix \& Calvete, 2016) and non-judging (Calvete et al., 2017) also directly predict a preference of online social interaction and both of them predict de- 
creased use of the Internet to regulate mood (Calvete et al., 2017; Gámez-Guadix \& Calvete, 2016), two additional components of the Cognitive-Behavioral Model. Moreover, the increased awareness attached to mindfulness is associated with increased self-regulation (Calvete et al., 2017; Gámez-Guadix \& Calvete, 2016; Tang et al., 2007); likely through encouraging positive meta-cognition about Internet use (Casale, Caplan, \& Fioravanti, 2016) and through improved executive control (Teper, Segal, \& Inzlicht, 2013).

In addition, mindfulness may reduce addiction behaviors through activating positive coping skills used to combat stressful life events. For instance, similarly to other addictions, individuals with social media addiction exhibit social media craving behaviors; an excessive desire to use social media (Savci \& Griffiths, 2019). Mindfulness, in this process, may have an inhibitory role in stress-coping through controlling craving behavior, automatic and unwanted thoughts in the addiction process (Li et al., 2017).

Two recent studies have examined the relationship between trait mindfulness and the components of the Cognitive-Behavioral Model. The first, a cross-sectional study, indicated that mindfulness was negatively associated with all components of Internet addiction (Gámez-Guadix \& Calvete, 2016). Longitudinal analyses within the second study revealed that components of trait mindfulness predicted the subsequent decrease of components of Internet addiction (Calvete et al., 2017). These results suggest that mindfulness may provide direct protection against Facebook and Internet addiction.

Even if mindfulness plays a direct role in ameliorating Facebook addiction, psychological problems could still serve important indirect roles. It may be difficult to maintain a mindful state when in the midst of depression and anxiety (Nejati, Zabihzadeh, Maleki,
\& Tehranchi, 2012). Similarly, it is possible that low self-esteem can discourage conscious self-awareness by making such awareness psychologically painful (Silvia, 2002). Low self-esteem would also entail negative self-judgments, countering the non-judgmental stance promoted by mindfulness. Such psychological issues could thus encourage compulsive behavior by weakening the protections provided by trait mindfulness.

If so, it would be congruent with the Cognitive-Behavioral Model, in that it would be mediating cognitive processes, rather than depression and anxiety themselves, that would directly connect to Facebook addiction (Caplan, 2010). Mindfulness, in such a model, would represent a viable path linking addictive behavior with psychological issues, as well as a marker indicating the potential presence of the cognitive components of Facebook addiction.

Despite our theorizing above positing that psychological problems indirectly relate to Facebook addiction through mindfulness (Błachnio et al., 2015; Koc \& Gulyagci, 2013), it is still possible that psychological problems and self-esteem may have a direct relation to Facebook addiction because of incidental factors other than mindfulness. Therefore, the present study also compared the "indirect model" with a second model that allowed for direct connections from psychological problems and self-esteem to Facebook addiction (a "direct model"). In doing so, we test the following additional hypotheses:

$H 2$ : Mindfulness will be negatively related to Facebook addiction.

$H 3$ : There will be indirect relationships between self-esteem, psychological problems and Facebook addiction that operate through mindfulness.

H4: An "indirect model", allowing self-esteem and psychological problems to only relate to Facebook addiction indirectly through 
mindfulness, will provide a better fit for the data than a "direct model", allowing self-esteem and psychological problems to connect to Facebook addiction directly.

We also consider a third possibility that mindfulness only relates to Facebook addiction because of the connection mindfulness shares with depression, anxiety, and other emotional problems. In that case, mindfulness interventions might alleviate symptoms of addiction by reducing anxiety and depression rather than directly impacting addictive behavior. This idea is consistent with previous correlational studies showing that mindfulness negatively relates to depressive symptoms (Carmody \& Baer, 2008; Raes et al., 2014) and to stress derived from compulsive social media use (Apaolaza, Hartmann, D'Souza, \& Gilsanz, 2019). Therefore, the present study tested an alternative structural model (which we label the "alternative model") which represented mindfulness as an indirect predictor of Facebook addiction through psychological symptoms and self-esteem. However, based on the Cognitive-Behavioral Model, as well as other findings in the literature (Elhai, Dvorak, Levine, \& Hall, 2017; Lee, Cheung, et al., 2012), we hypothesized that:

H5: The "indirect model" will provide a better fit for the data than an "alternative model", which posits that mindfulness, rather than psychological issues and self-esteem, serves as an indirect predictor of Facebook addiction.

\section{Method}

\section{Participants and Procedures}

We recruited 416 college students from three universities in Turkey via classroom announcements. Participants completed the surveys in paper form during class time after an informed consent process. After excluding those with incomplete surveys $(n=12)$, with missing data on model variables $(n=4)$, outliers $(n=4)$, and those that indicated they did not use Facebook ( $n=98,24.7 \%), 298$ individuals were included in the final sample. A power analysis using RMSEA to compute the statistical power of a structural model (Preacher $\&$ Coffman, 2006) revealed that the statistical power of the present study is .98 , showing that it has adequate statistical power. The sample included 191 (64.1\%) female and 107 $(35.9 \%)$ male students, ranging in age from 18 to 40 years $(M=21.61, S D=2.20)$. Half of the participants reported that they spent less than 1 hour a day on Facebook, 38\% reported that they spent 1-2 hours on Facebook, and $8 \%$ reported that they spent more than 2 hours on Facebook. Fifty-seven percent of the participants stated that they checked their status less than 2 times a day, 22\% stated that they checked their status 3-5 times a day, and $21 \%$ stated that they checked their status more than 6 times a day.

\section{Measures}

Chen Internet Addiction Scale (CIAS). We used the CIAS (Chen, Weng, Su, Wu, \& Yang, 2003) to measure participants' addictive Facebook use, modifying the scale to refer to "Facebook" when the scale otherwise referenced "the internet" (e.g., "I feel nervous, when I'm not connected to the Facebook for a certain time", "I realize that I spend more and more time on Facebook"). The CIAS has 26 items with a four-point Likert scale and five dimensions including compulsive use, withdrawal, tolerance, problems in interpersonal relationships and health/time management. Higher scores show increasing addictive use of Facebook. The Turkish form of the CIAS has high internal reliability $(\alpha=.93)$ and high correlations among sub-scales (Ceyhan et al., 2019).

The Depression Anxiety Stress Scale (DASS). The DASS is a 42-item self-report instrument 
(Lovibond \& Lovibond, 1995) designed to measure three related emotional states: depression (e.g., "I couldn't seem to experience any positive feeling at all."), anxiety (e.g., "I found myself in situations that made me so anxious I was most relieved when they ended.") and stress (e.g., "I found myself getting upset by quite trivial things."). The Turkish version of DASS demonstrated high internal reliability ( $\alpha=.90, .92$ and 92 for depression, anxiety and stress respectively; (Akın \& Çetin, 2007) and exhibited high test-retest reliability (.98).

Rosenberg Self-Esteem Scale (RSS). We assessed self-esteem using the RSS (Rosenberg, 1965), which has 10 items on a 4-point Likert scale (e.g., "I take a positive attitude toward myself'). Higher scores of the RSS indicate higher levels of self-esteem. The RSS was adapted to Turkish culture by Çuhadaroğlu (1986), with high internal reliability and test-retest reliability scores (85 and .71, respectively).

Mindful Attention Awareness Scale (MAAS). We administered the MAAS, a 15-item sixpoint Likert scale (range going from $1=A$ ways to $6=$ Never) developed by Brown and Ryan (2003), to measure trait mindfulness (e.g., "I could be experiencing some emotion and not be conscious of it until sometime lat$\left.e r^{\prime \prime}\right)$, with higher scores indicating higher levels of mindfulness. The Turkish form of the MAAS (Özyesil, Arslan, Kesici, \& Deniz, 2011) is composed of a single factor with acceptable internal reliability $(.80)$ and high test-retest reliability (.86).

\section{Data Analyses}

We carried out an SEM path analysis to examine the relationships among variables as well as the role of mindfulness in Facebook addiction. Though it uses similar procedures, this analysis should not be confused with a mediation analysis, which requires an estab- lished temporal ordering between variables (MacKinnon, Cheong, \& Pirlott, 2012). SEM analysis was performed in LISREL 8 developed by Jöreskog and Sörbom (2004). We used skewness and kurtosis scores to examine normality, and determined outliers using Mahalanobis distance (Kline, 2015). Because the Common Method Bias (CMB), wherein variation in responses is attributable to the measurement method rather than to the constructs the measures represent, is a potential problem in behavioral research (Podsakoff, MacKenzie, \& Podsakoff, 2003), we also conducted two additional tests, the common latent factor and Harman's single factor tests, to test for $\mathrm{CMB}$.

After assessing the measurement model, we tested a model using depression, anxiety, and stress (as indicators of psychological problems), as well as self-esteem, to predict mindfulness, which in turn predicted Facebook Addiction (we term this the "indirect model"; see Figure 2). We also compared this model with a second model that allowed for direct connections from psychological problems and self-esteem to Facebook addiction (a "direct model"). We then used a third model to test whether mindfulness should instead be an indirect predictor of mindfulness through psychological problems and self-esteem (an "alternative model"; see Figure 3). We used conventional model fit statistics and their cut-off points (showing in parentheses) to assess goodness-of-fit (Hu \& Bentler, 1999; Schermelleh-Engel, Moosbrugger, \& Müller, 2003), such as the RMSEA (<.08), SRMR $(<.10), \mathrm{NFI}(>.90), \mathrm{CFI}(>.95), \mathrm{GFI}(>.90)$, and IFI (> .90). We also used scaled chi-square difference tests $\left(\Delta \chi^{2}\right)$ to compare nested models, and differences in the Bayesian Information Criterion (BIC) to compare non-nested models, with a difference of at least 10 used to indicate whether a model should be preferred (Raftery, 1995). 


\section{Results}

As part of our preliminary analyses, after analyzing normality and outliers, we checked the model for CMB, using Harman's single factor test and common latent factor (Podsakoff et al., 2003). In Harman's single-factor test, we ran exploratory factor analysis where all variables are loaded into a single factor and examined the unrotated factor solution. This analysis indicated that a single factor explained only $22 \%$ of the total variance. To confirm these results, we performed a common latent factor test where all manifest variables were related to a new latent variable. Results from this analysis demonstrated that the common method factor accounted for only $29 \%$ of the total variance. These results showed the common method variance being less than $50 \%$, meaning that one general factor did not account for the majority of the covariance among the measures and that $\mathrm{CMB}$ was not a likely contaminant of this study.

In our analysis, we followed Anderson and Gerbing's (1988) two-step SEM procedure, performing a confirmatory factor analysis of the measurement model prior to testing our structural model. Table 1 includes descriptive statistics and a correlation matrix for model variables. Consistent with $\mathrm{H} 1 \mathrm{a}$ and $\mathrm{H} 1 \mathrm{~b}$, each measure of psychological issues was significantly and positively related to Facebook addiction ( $r=.28, .33$, and .20, respectively, for depression, anxiety, and stress measures, all ps < .01.), and self-esteem was negatively related to Facebook addiction (though somewhat weakly, $r=-.15, p<.05)$. Given these significant associations, we proceeded to test whether mindfulness could account for those associations using path analysis. As some variables violated assumptions of normality, we used the Satorra-Bentler scaled chi-square (Satorra \& Bentler, 1988), a maximum likelihood procedure robust to normality violations.

\section{Measurement Model}

Depression, anxiety and stress, subscales of the DASS, were used as observed indicators of the latent variable of psychological symptoms. Similarly, CIAS subscales were used to determine the latent construct of Facebook addiction. For self-esteem and mindfulness, we created three observed indicators (or "parcels") for each latent variable, using exploratory factor analysis to create the indicators (Russell, Kahn, Spoth, \& Altmaier, 1998). The items were rank ordered based on their factor loadings. We then sequentially assigned pairs of the highest and lowest items to an indicator to equate their average loadings.

Table 1 Correlation matrix and descriptive statistics

\begin{tabular}{|c|c|c|c|c|c|c|}
\hline & 1 & 2 & 3 & 4 & 5 & 6 \\
\hline 1 - Facebook Addiction & -- & & & & & \\
\hline 2 - Mindfulness & $-.31 * *$ & -- & & & & \\
\hline 3 - Self-esteem & $-.15^{*}$ & $.40 * *$ & -- & & & \\
\hline 4 - Depression & $.28 * *$ & $-.46 * *$ & $-.47 * *$ & -- & & \\
\hline 5 - Anxiety & $.33^{* *}$ & $-.53 * *$ & $-.33 * *$ & $.73 * *$ & -- & \\
\hline 6 - Stress & $.20 * *$ & $-.45^{* *}$ & $-.27 * *$ & $.70 * *$ & $.75^{* *}$ & -- \\
\hline Mean & 32.51 & 58.51 & 31.27 & 9.80 & 10.12 & 15.63 \\
\hline$S d$ & 9.42 & 11.56 & 5.07 & 8.29 & 7.51 & 8.60 \\
\hline$\tau_{5}$ & .94 & .85 & .86 & .92 & .89 & .90 \\
\hline
\end{tabular}


The measurement model had good model fit $\left(\chi^{2}=165.04, d f=71, \chi^{2} / d f=2.324, p<\right.$ $.001, \mathrm{RMSEA}=.067$ [90\% confidence interval $(\mathrm{Cl})=.054-.080], \mathrm{SRMR}=.052, \mathrm{GFI}=.93$, $\mathrm{CFI}=.98, \mathrm{NFI}=.96, \mathrm{IFI}=.97)$. Each observed variable significantly loaded on its respective latent variable. Intercorrelations among the latent variables were significant at .01 level, as shown in Figure 1.

\section{Structural Models}

We first examined our "indirect model" connecting psychological symptoms and self-es- teem with Facebook addiction through mindfulness. To this end, the specified structural model fit the data well, $S$ - $B$ scaled $\chi^{2}=188.30$, $d f=83, \chi^{2} / d f=2.27, p<.001$ (RMSEA $=.060$ [90\% confidence interval $(\mathrm{Cl})=.048-.073$ ], $\mathrm{SRMR}=.055, \mathrm{GFI}=.93, \mathrm{CFI}=.96, \mathrm{NFI}=.93$, $I F I=.96)$. Standardized regression coefficients indicated that psychological symptoms negatively predicted mindfulness $(\theta=-.54, S E=$ $.055, p<.001)$ and self-esteem positively predicted mindfulness $(B=.21, S E=.06, p<.001)$. Moreover, mindfulness was significantly and inversely associated with Facebook addiction ( $6=-.38, S E=.06, p<.001)$, as we predicted

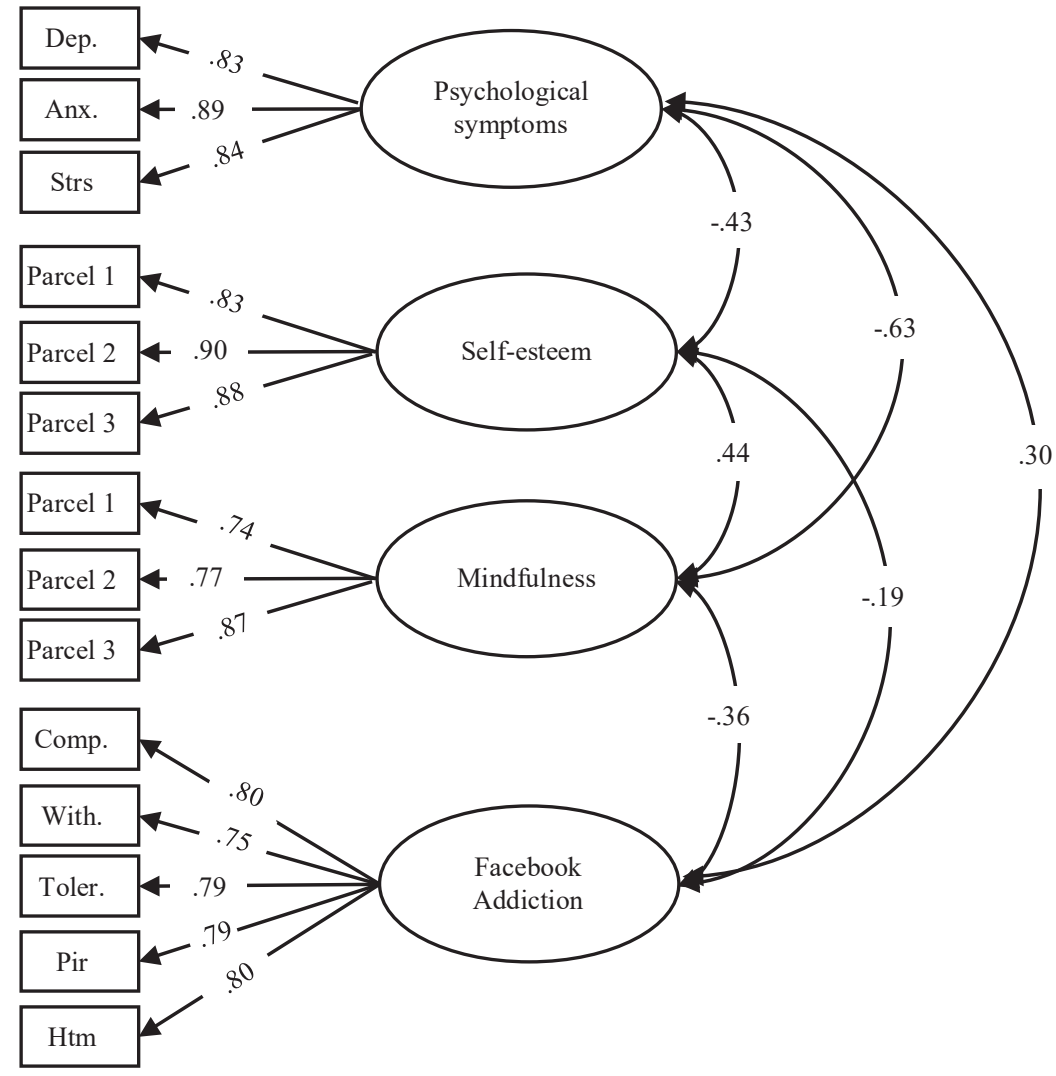

Figure 1 Measurement model.

Note. Dep: Depression, Anx: Anxiety, Strs: Stress, Comp: Compulsive use, With: Withdrawal, Toler: Tolerance, Pir: Problems in interpersonal relationships, Htm: Health/time management. 


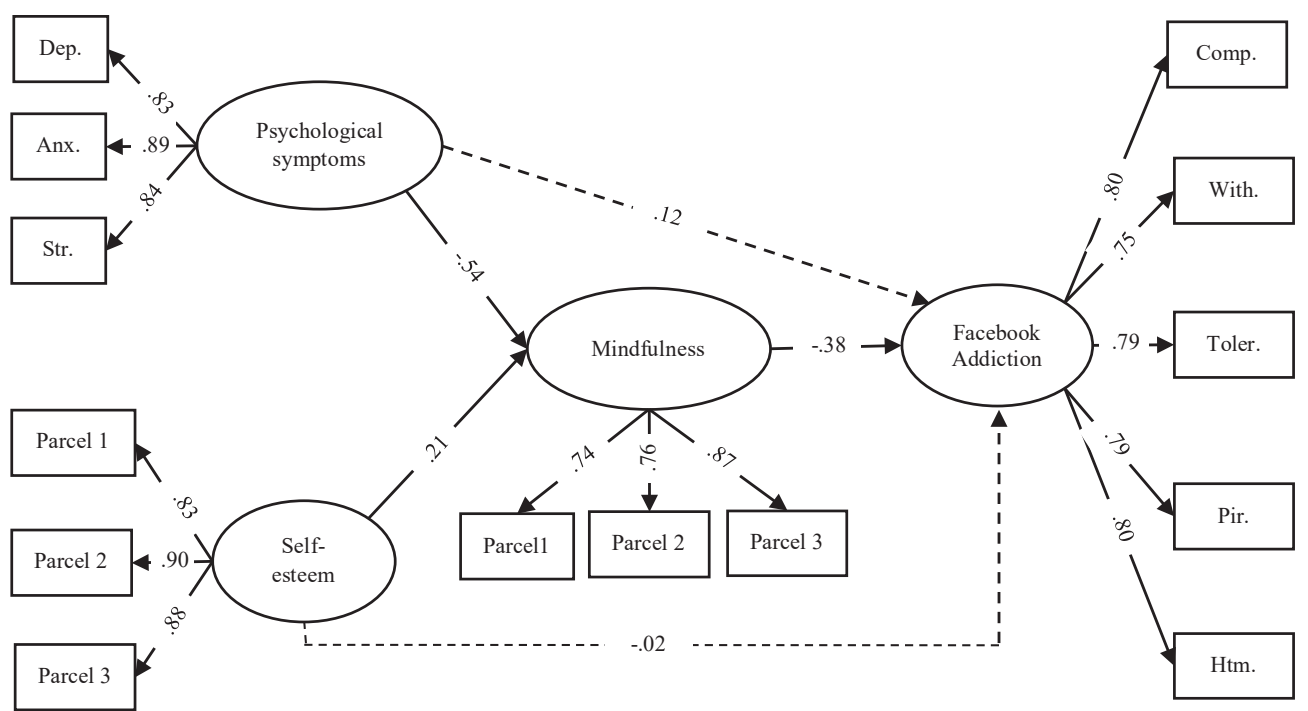

Figure 2 Structural model (Indirect model) demonstrating standardized regression confidents between variables. Dashed lines represent direct paths tested in "direct model".

Note. Dep: Depression, Anx: Anxiety, Strs: Stress, Comp: Compulsive use, With: Withdrawal, Toler: Tolerance, Pir: Problems in interpersonal relationships, Htm: Health/time management. All coefficients greater than .20 are significant at $p<.001$.

in $\mathrm{H} 2$. The hypothesized model accounted for $14 \%$ of unique variance in Facebook addiction (Figure 2). ${ }^{1}$

We compared the "indirect model" with a "direct model", which allowed for direct associations between psychological symptoms and self-esteem with Facebook addiction. This model also fit the data well, $S-B$ scaled $\chi^{2}=172.43, d f=71, \chi^{2} / d f=2.43, p<.001$ (RMSEA $=.069[90 \%$ confidence interval $(\mathrm{Cl})=$ $.056-.082]$, SRMR $=.052, \mathrm{GFI}=.93, \mathrm{CFI}=.96$, $\mathrm{NFI}=.93, \mathrm{IFI}=.96)$. However, both psychological symptoms and self-esteem fell short of significance in predicting Facebook addiction (see the dashed lines in Figure 2). A Bryant-

${ }^{1}$ Models testing gender differences suggested that coefficients did not significantly differ between men and women $\left(\Delta \chi^{2}=12.575, d f=29, p=.997\right)$. Supplementary analyses are available upon request.
Satorra scaled chi-square difference test (Bryant \& Satorra, 2012) was non-significant $\left(\Delta \chi^{2}=4.32, d f=12, p=.977\right)$. This suggests that the indirect model should be preferred to the direct model.

We also tested our "alternative model", which represented mindfulness as an indirect predictor of Facebook addiction through psychological symptoms and self-esteem (as shown in Figure 3). This third model produced substantially worse fit statistics in comparison with the indirect model, $S-B$ scaled $\chi^{2}=206.18, d f=83, \chi^{2} / d f=2.48, p<.001$ (RMSEA $=.066[90 \%$ confidence interval $(\mathrm{Cl})=.053-.78]$, SRMR $=.068, \mathrm{GFI}=.91$, $\mathrm{CFI}=.95, \mathrm{NFI}=.92, \mathrm{IFI}=.95)$. A comparison of $\mathrm{BIC}$ values suggested that the indirect model should be highly preferred, $\triangle B I C=16.2$. When allowing for a direct path between mindfulness and Facebook addiction, that path was 


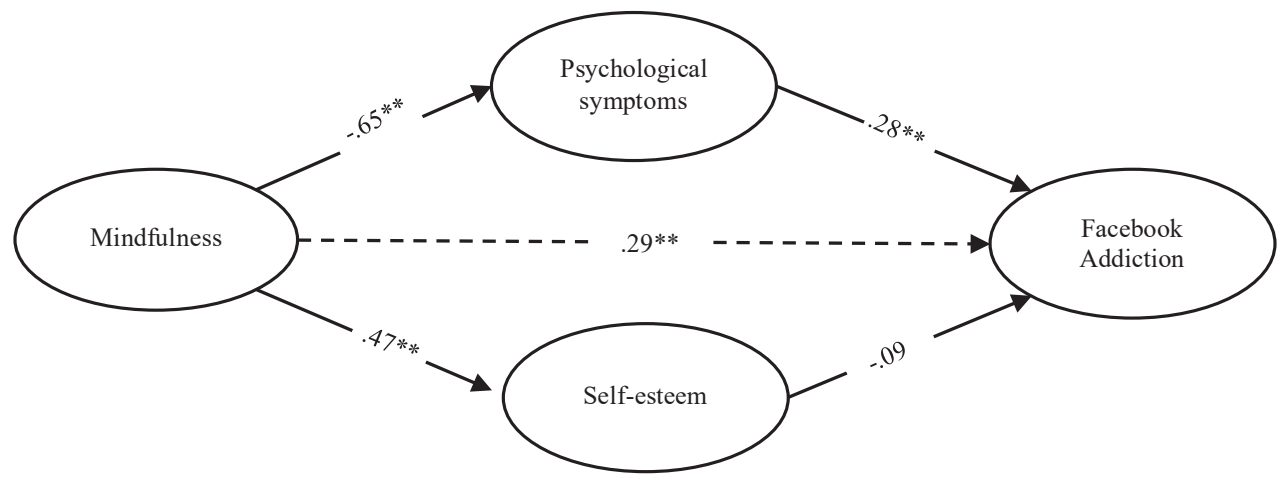

Figure 3 An alternative model with an indirect relationship between mindfulness and Facebook addiction. The dashed line represents a direct path tested in a separate model.

Note. ${ }^{* *} p<001$.

highly significant, $b=.29$, [.103], $p<.01$, $\Delta \mathrm{BIC}=12.7$.

Overall, these results provide support for $\mathrm{H} 3, \mathrm{H} 4$, ad $\mathrm{H} 5$ suggesting that self-esteem and psychological issues are indirect predictors of Facebook addiction, and that mindfulness can plausibly account for that connection, itself being a direct predictor of addiction.

\section{Discussion}

The purpose of our study was to clarify the role of mindfulness in the connection between psychological issues and Facebook addiction. We hypothesized that the overall connections that psychological issues and self-esteem shared with Facebook addiction (predicted in $\mathrm{H} 1 \mathrm{a}$ and $\mathrm{H} 1 \mathrm{~b}$, respectively) would be explained by the connection between Facebook addiction and trait mindfulness (with that correlation predicted in $\mathrm{H} 2$ ). In particular, we predicted that the psychological issues and self-esteem would relate to Facebook addiction indirectly through mindfulness (H3), with model comparisons favoring an "indirect model" in comparison with a "direct model" (with direct connections between psychological issues/self-esteem and Facebook addiction; $\mathrm{H} 4$ ), and to an "alternative model" (with mindfulness connecting to Facebook addiction indirectly through psychological issues/self-esteem; H5).

Results from the SEM analysis support our hypotheses. Zero-order correlations provided support for $\mathrm{H} 1 \mathrm{a}$ and $\mathrm{H} 1 \mathrm{~b}$, showing a positive association between Facebook addiction and psychological problems and a negative association with self-esteem. Our results also supported $\mathrm{H} 2$, with mindfulness negatively predicting Facebook addiction. Furthermore, our results suggest that the connection between mindfulness and Facebook addiction is direct, and fully accounts for the associations that Facebook addiction shares with psychological problems and self-esteem (H3). These results help to clarify the nature of the connection between mindfulness and addiction, a connection left unclear by prior research. Though it may have been plausible for mindfulness to play an indirect role, with psychological issues connecting in a more direct way to Facebook addiction (Carmody \& 
Baer, 2008; Raes et al., 2014), the evidence favors mindfulness as a proximal factor, one that might directly mitigate against addictive behaviors. Psychological issues, on the other hand, as well as self-esteem, show no significant direct connection with Facebook addiction when accounting for mindfulness (H4), and an alternative model testing mindfulness as an indirect predictor through psychological problems and self-esteem was not preferred (H5). These findings are consistent with the Cognitive-Behavioral Model (Caplan, 2010; Davis, 2001), which suggest that the connection between psychological issues and addiction works indirectly through mediating cognitive processes.

Our findings indicating a direct role for mindfulness make sense in light of the available literature. Each of the four components of the Cognitive-Behavioral Model have shown to be connected to mindfulness, including the connection between decreased self-judgment and decreased preference for online social interaction (Beauchemin et al., 2008; Dekeyser et al., 2008); the connection between improved self-awareness and mood regulation (Roemer, Williston, \& Rollins, 2015) and improved self-regulation (Calvete et al., 2017; Gámez-Guadix \& Calvete, 2016; Tang et al., 2007), as well as the implications of these connections for negative health outcomes (Sriwilai \& Charoensukmongkol, 2016). Consequently, our findings provide further support for the importance of mindfulness as a direct barrier to Facebook addiction, one that functions independently of its connection to depression, anxiety, or self-esteem (Carmody \& Baer, 2008; Raes et al., 2014), being itself a promoter of offline social interaction, as well as healthy regulation strategies. These conclusions are further supported by the ability for mindfulness to predict addiction risk even when controlling for the psychological issues examined in this study.
That psychological issues would lack a direct connection to Facebook addiction may seem unusual, but studies suggest that such as indirect connection through mindfulness is plausible. Depression, anxiety, and low self-esteem may serve to lower trait mindfulness by hindering concentration, by discouraging self-awareness, and by fostering negative self-judgments (Nejati et al., 2012; Silvia, 2002). This lowered trait mindfulness, in turn, would increase the risk of Facebook addiction, as lower mindfulness would entail decreased self-regulation and an increased preference for online social interactions. Our results help clarify the role of mindfulness as a barrier against problematic Facebook use, and as a factor that could be substantially weakened by the presence of psychological issues.

The same dynamics might apply to social media addiction more generally. Sriwilai and Charoensukmongkol (2016) focused on the consequences of social media addiction and found that people with high addiction to social media tended to have lower trait mindfulness than those with lower addiction. However, unlike our study, they argued that compulsion to use social media caused the lack of mindfulness. However, they also found that low levels of trait mindfulness were related to emotion-focused coping, suggesting that mindfulness has the potential to mitigate the tendency of those with social media addiction to relieve their stress through social media use. These findings, on the other hand, support our hypothesis that detrimental effects of psychological problems on mindfulness may lead to people using Facebook as a stress-reduction strategy.

On the other hand, there may also be a circular relationship between mindfulness and Internet addiction, where mindfulness could have both a preventive role on the formation of the addiction process and may have a 
protective role against the negative effects of compulsive internet use. Supporting the protective role of mindfulness, previous studies indicated that mindfulness moderate the relationship between the intensity of social media use and emotional exhaustion (Charoensukmongkol, 2016b) and demonstrated that individuals who lack mindfulness would have difficulty controlling their social media use (Kuss \& Griffiths, 2011). Nevertheless, similar to our study, literature also supports the preventive role of mindfulness, suggesting that mindfulness might help individuals to regulate their social media behaviors (Calvete et al., 2017; Charoensukmongkol, 2016a; Gámez-Guadix \& Calvete, 2016). Similar results have been found for self-esteem, where those with higher levels of mindfulness are likely to also have higher self-esteem, which in turn contributes to a decrease in social anxiety and compulsive use of mobile social media (Apaolaza et al., 2019). It would be fruitful for future research to test our proposed models using social media addiction, to see whether our results hold for that broader concept.

It is worth noting the implications of our findings for the distinction between self-esteem and mindfulness. Research suggests that self-esteem and mindfulness are overlapping but distinct constructs (as supported by the observed zero-order correlation between the two in the present study; $r=.40$ ), with some, such as Ryan and Brown (2003), proposing mindfulness as a healthier alternative to self-esteem. Our results suggest that, in terms of Facebook addiction, there are aspects of mindfulness that contribute to decreased addiction in ways that self-esteem does not. The open and nonjudgmental approach that characterizes mindfulness may play an important role in that regard. Mindfulness' focus on nonjudgmental attention (Kabat-Zinn, 2009) may lead one to fully accept him/herself as a valuable person (Sha- piro, Carlson, Astin, \& Freedman, 2006), decreasing the need for Facebook as compensation for low self-esteem (Shapiro et al., 2006), consistent with Social Compensation Theory. This would serve not only to reduce addiction, but may also help improve self-esteem itself (Pepping et al., 2013).

For Facebook users, these findings have a certain set of implications. They imply that users with lower trait mindfulness are going to be more likely to use Facebook in compulsive ways relative to their high-mindfulness counterparts. They also imply that those who find their Facebook use problematic should consider ways to increase their trait mindfulness, particularly if they are prone to depression and anxiety, or have low self-esteem. The increased self-awareness and concentration that accompanies increased trait mindfulness could be a substantial boon to any effort to curtail addictive behavior in the context of Facebook use.

The present study also has some notable limitations. Our cross-sectional approach precludes examining the causal relationship between variables or establishing mindfulness as a true mediator between psychological issues and Facebook addiction, which would be better assessed with experimental or longitudinal designs. The use of self-report questionnaires may also limit the validity of our findings, and our convenient, college-age sample may limit its applicability to younger adolescents or older adults. Also, though it is helpful to see the dynamics of Facebook addiction in a non-Western context, the present study was not able to provide direct cross-cultural comparisons for the present models. It is possible that aspects of our findings might be altered in other types of non-Western contexts. Overall, we would greatly welcome experimental research that directly tests the effectiveness of mindfulness interventions in reducing addictive behavior, particularly lon- 
gitudinal studies that would allow for robust mediation analysis.

It is also worth noting that our sample was non-clinical, and may not reflect the role of mindfulness in those experiencing severe forms of Facebook addiction. Available definitions of Facebook or social media addiction provide little insight into the specific parameters of use that would define addiction (Andreassen \& Pallesen, 2014). At what point does Facebook use begin to impair one's life; how much time and effort devoted to Facebook is "too much"; what constitutes "uncontrollable motivation" - these types of questions are difficult to answer in any domain of addiction, and would likely be different in each individual case. Nevertheless, according to Ko et al.'s (2005) suggestion, results from our sample would suggest that Facebook addiction is rare, with only eleven individuals (3.7\%) meeting the criterion for addiction risk. Additional research that specifically targets those with more severe addiction symptoms would be valuable.

The present study represents an important contribution to the literature on mindfulness and Facebook addiction by showing how mindfulness accounts for the association between psychological problems, self-esteem and Facebook addiction. It helps confirm mindfulness as one of the opposing forces to problematic Facebook use, in that it negatively predicts Facebook addiction, supports psychological issues and self-esteem as indirect predictors of addictive symptoms. The present study also extends previous findings to a Turkish context. We hope that our findings can be useful to researchers and clinicians in helping to further understand the construct and in seeking to help those suffering from or at risk of Facebook addiction. Such findings may also be useful to individuals looking for help managing their own Facebook use.

\section{Acknowledgement}

We would like to acknowledge the precious contribution of N. Kemal Haspolat and Murat Ağırkan on data collection. We wish to thank Yasemin Haspolat who contributed to the editing of this paper and students who participated in this study.

\section{Authors' ORCID}

\author{
Mustafa Eşkisu \\ https://orcid.org/0000-0002-7992-653X \\ Zekeriya Çam \\ https://orcid.org/0000-0002-2965-2390 \\ Sedat Gelibolu \\ https://orcid.org/0000-0002-9451-7435 \\ Kyler Ray Rasmussen \\ https://orcid.org/0000-0002-8532-6485
}

\section{References}

Akın, A., \& Çetin, B. (2007). The Depression Anxiety and Stress Scale (DASS): The study of validity and reliability. Educational Sciences: Theory \& Practice, 7(1), 260-268.

Alexa (2018). Top sites. https://www.alexa.com/ $\underline{\text { topsites }}$

Anderson, J. C., \& Gerbing, D. W. (1988). Structural equation modeling in practice: A review and recommended two-step approach. Psychological Bulletin, 103(3), 411-423. doi: 10.1037/00332909.103.3.411

Andreassen, C., \& Pallesen, S. (2014). Social network site addiction - An overview. Current Pharmaceutical Design, 20(25), 4053-4061. doi: 10.2174/13816128113199990616

Apaolaza, V., Hartmann, P., D'Souza, C., \& Gilsanz, A. (2019). Mindfulness, compulsive mobile social media use, and derived stress: The mediating roles of self-esteem and social anxiety. $\mathrm{Cy}$ berpsychology, Behavior, and Social Networking, 22(6), 388-396. doi: 10.1089/cyber.2018.0681

Balcı, Ş., \& Gölcü, A. (2013). Facebook addiction among university students in Turkey: "Selcuk 
University example". Journal of Studies in Turkology, 34, 255-278. doi: 10.4103/2278-344x. 149234

Beauchemin, J., Hutchins, T. L., \& Patterson, F. (2008). Mindfulness meditation may lessen anxiety, promote social skills, and improve academic performance among adolescents with learning disabilities. Complementary Health Practice Review, 13(1), 34-45. doi: 10.1177/1533210107311624

Bishop, S. R., Lau, M., Shapiro, S., Carlson, L., Anderson, N. D., Carmody, J., . . . \& Devins, G. (2004). Mindfulness: A proposed operational definition. Clinical Psychology: Science and Practice, 11(3), 230-241. doi: 10.1093/clipsy.bph077

Błachnio, A., Przepiorka, A., Benvenuti, M., Cannata, D., Ciobanu, A. M., Senol-Durak, E., . . \& \& Pappas, I. O. (2016). An international perspective on Facebook intrusion. Psychiatry Research, 242, 385-387. doi: 10.1016/j.psychres.2016.06.015

Błachnio, A., Przepiórka, A., Gorbaniuk, O., Benvenuti, M., Ciobanu, A. M., Senol-Durak, E., . . . Ben-Ezra, M. (2019). Cultural correlates of internet addiction. Cyberpsychology, Behavior, and Social Networking, 22(4), 258-263. doi: 10.1089/cyber.2018.0667

Błachnio, A., Przepiórka, A., \& Pantic, I. (2015). Internet use, Facebook intrusion, and depression: Results of a cross-sectional study. European Psychiatry, 30(6), 681-684. doi: 10.1016/j.eurpsy.2015.04.002

Błachnio, A., Przepiorka, A., Senol-Durak, E., Durak, M., \& Sherstyuk, L. (2017). The role of personality traits in Facebook and Internet addictions: A study on Polish, Turkish, and Ukrainian samples. Computers in Human Behavior, 68, 269-275. doi: 10.1016/j.chb.2016.11.037

Bluth, K., \& Blanton, P. W. (2014). Mindfulness and self-compassion: Exploring pathways to adolescent emotional well-being. Journal of Child and Family Studies, 23(7), 1298-1309. doi: 10.1007/ s10826-013-9830-2

Bowen, S., \& Enkema, M. C. (2014). Relationship between dispositional mindfulness and substance use: Findings from a clinical sample. Addictive Behaviors, 39(3), 532-537. doi: 10.1016/j.addbeh.2013.10.026

Bögels, S., Hoogstad, B., van Dun, L., de Schutter, S., \& Restifo, K. (2008). Mindfulness training for adolescents with externalizing disorders and their parents. Behavioural and Cognitive Psychotherapy, 36(2), 193-209. doi: 10.1017/ S1352465808004190

Brown, K. W., \& Ryan, R. M. (2003). The benefits of being present: Mindfulness and its role in psychological well-being. Journal of Personality and Social Psychology, 84(4), 822-848. doi: 10.1037/0022-3514.84.4.822

Bryant, F. B., \& Satorra, A. (2012). Principles and practice of scaled difference chi-square testing. Structural Equation Modeling: A Multidisciplinary Journal, 19(3), 372-398. doi: 10.1080/10705511.2012.687671

Calvete, E., Gámez-Guadix, M., \& Cortazar, N. (2017). Mindfulness facets and problematic Internet use: A six-month longitudinal study. $\mathrm{Ad}$ dictive Behaviors, 72, 57-63. doi: 10.1016/j.addbeh.2017.03.018

Caplan, S. E. (2010). Theory and measurement of generalized problematic Internet use: A two-step approach. Computers in Human Behavior, 26(5), 1089-1097. doi: 10.1016/j.chb.2010.03.012

Carmody, J., \& Baer, R. A. (2008). Relationships between mindfulness practice and levels of mindfulness, medical and psychological symptoms and well-being in a mindfulness-based stress reduction program. Journal of Behavioral Medicine, 31(1), 23-33. doi: 10.1007/s10865-0079130-7

Casale, S., Caplan, S. E., \& Fioravanti, G. (2016). Positive metacognitions about Internet use: The mediating role in the relationship between emotional dysregulation and problematic use. Addictive Behaviors, 59, 84-88. doi: 10.1016/j. addbeh.2016.03.014

Ceyhan, E., Boysan, M., \& Kadak, M. T. (2019). Associations between online addiction, attachment style, emotion regulation, depression and anxiety in general population: Testing the proposed diagnostic criteria for internet addiction. Sleep and Hypnosis: A Journal of Clinical Neuroscience and Psychopathology, 21(2), 123-139. doi: 10.5350/Sleep.Hypn.2019.21.0181

Charoensukmongkol, P. (2016a). Contribution of mindfulness to individuals' tendency to believe and share social media content. International Journal of Technology and Human Interaction (IJTHI), 12(3), 47-63. doi: 10.4018/ IJTHI.2016070104 
Charoensukmongkol, P. (2016b). Mindful Facebooking: The moderating role of mindfulness on the relationship between social media use intensity at work and burnout. Journal of Health Psychology, 21(9), 1966-1980. doi: 10.1177/1359105315569096

Chen, S.-H., Weng, L.-J., Su, Y.-J., Wu, H.-M., \& Yang, P.-F. (2003). Development of a Chinese Internet Addiction Scale and its psychometric study. Chinese Journal of Psychology, 45(3), 279-294. doi: 10.1037/t44491-000

Ciesla, J. A., Reilly, L. C., Dickson, K. S., Emanuel, A S., \& Updegraff, J. A. (2012). Dispositional mindfulness moderates the effects of stress among adolescents: Rumination as a mediator. Journal of Clinical Child \& Adolescent Psychology, 41(6), 760-770. doi: 10.1080/15374416.2012.698724

Çuhadaroğlu, F. (1986). Adolesanlarda benlik saygISI [Self-esteem in adolescents]. (Unpublished medical speciality thesis), Hacettepe University, Ankara.

Davis, R. A. (2001). A cognitive-behavioral model of pathological Internet use. Computers in Human Behavior, 17(2), 187-195. doi: 10.1016/S07475632(00)00041-8

Dekeyser, M., Raes, F., Leijssen, M., Leysen, S., \& Dewulf, D. (2008). Mindfulness skills and interpersonal behaviour. Personality and Individual Differences, 44(5), 1235-1245. doi: 10.1016/ S0747-5632(00)00041-8

Elhai, J. D., Dvorak, R. D., Levine, J. C., \& Hall, B. J. (2017). Problematic smartphone use: A conceptual overview and systematic review of relations with anxiety and depression psychopathology Journal of affective disorders, 207, 251-259. doi: 10.1016/j.jad.2016.08.030

Eşkisu, M., Hoşoğlu, R., \& Rasmussen, K. (2017). An investigation of the relationship between Facebook usage, Big Five, self-esteem and narcissism. Computers in Human Behavior, 69, 294-301. doi: 10.1016/j.chb.2016.12.036

Facebook $^{\circ}$ (2018). Stats. https://newsroom.fb.com/ company-info/

Gámez-Guadix, M., \& Calvete, E. (2016). Assessing the relationship between mindful awareness and problematic internet use among adolescents. Mindfulness, 7(6), 1281-1288. doi: 10.1007/s12671-016-0566-0

Göregenli, M. (1997). Individualist-collectivist tendencies in a Turkish sample. Journal of Cross-
CulturalPsychology,28(6),787-794.doi:10.1177/ 0022022197286009

Herrera, M., Pacheco, M., Palomar, J., \& Zavala, D. (2010). Facebook addiction related to low self-esteem, depression and lack of social skills. Psicología Iberoamericana, 18(1), 6-18.

Hu, L. T., \& Bentler, P. M. (1999). Cutoff criteria for fit indexes in covariance structure analysis: Conventional criteria versus new alternatives. Structural Equation Modeling: A Multidisciplinary Journal, 6(1), 1-55. doi: 10.1080/10705519909540118

Iskender, M., \& Akin, A. (2011). Self-compassion and Internet addiction. Turkish Online Journal of Educational Technology-TOJET, 10(3), 215-221.

Jöreskog, K. G., \& Sörbom, D. (2004). LISREL 8.71: Lincolnwood, IL: Scientific Software International.

Kabat-Zinn, J. (2009). Wherever you go, there you are: Mindfulness meditation in everyday life: Hachette Books.

Kanat-Maymon, Y., Almog, L., Cohen, R., \& Amichai-Hamburger, Y. (2018). Contingent selfworth and Facebook addiction. Computers in Human Behavior, 88, 227-235. doi: 10.1016/j. chb.2018.07.011

Kircaburun, K., \& Griffiths, M. D. (2018). Instagram addiction and the Big Five of personality: The mediating role of self-liking. Journal of Behavioral Addictions, 7(1), 158-170. doi: 10.1556/2006.7.2018.15

Kline, R. B. (2015). Principles and practice of structural equation modeling. New York: Guilford Press.

Ko, C.-H., Yen, J.-Y., Yen, C.-F., Chen, C.-S., \& Chen, C.-C. (2012). The association between Internet addiction and psychiatric disorder: A review of the literature. European Psychiatry, 27(1), 1-8. doi: 10.1016/j.eurpsy.2010.04.011

Ko, C. H., Yen, C. F., Yen, C. N., Yen, J. Y., Chen, C. C., \& Chen, S. H. (2005). Screening for Internet addiction: An empirical study on cut-off points for the Chen Internet Addiction Scale. The Kaohsiung Journal of Medical Sciences, 21(12), 545-551.

Koc, M., \& Gulyagci, S. (2013). Facebook addiction among Turkish college students: The role of psychological health, demographic, and usage characteristics. Cyberpsychology, Behavior, and Social Networking, 16(4), 279-284. doi: 10.1089/ cyber.2012.0249 
Kuss, D. J., \& Griffiths, M. D. (2011). Online social networking and addiction-a review of the psychological literature. International Journal of Environmental Research and Public Health, 8(9), 3528-3552. doi: 10.3390/ijerph8093528

Lau, M. A., Bishop, S. R., Segal, Z. V., Buis, T., Anderson, N. D., Carlson, L., . . . \& Devins, G. (2006). The Toronto Mindfulness Scale: Development and validation. Journal of Clinical Psychology, 62(12), 1445-1467. doi: 10.1002/jclp.20326

Lee, J. R., Moore, D. C., Park, E.-A., \& Park, S. G. (2012). Who wants to be "friend-rich"? Social compensatory friending on Facebook and the moderating role of public self-consciousness. Computers in Human Behavior, 28(3), 10361043. doi: 10.1016/j.chb.2012.01.006

Lee, R. M., \& Robbins, S. B. (1998). The relationship between social connectedness and anxiety, self-esteem, and social identity. Journal of Counseling Psychology, 45(3), 338-345. doi: 10.1037/0022-0167.45.3.338

Lee, Z. W., Cheung, C. M., \& Thadani, D. R. (2012). An investigation into the problematic use of Facebook. Procedinggs of the 45th Hawaii International Conference on System Science, 17681776. doi: 10.1109/HICSS.2012.106

Li, W., Garland, E. L., O’Brien, J. E., Tronnier, C., McGovern, P., Anthony, B., \& Howard, M. O. (2017). Mindfulness-oriented recovery enhancement for video game addiction in emerging adults: Preliminary findings from case reports. International Journal of Mental Health and Addiction, 16(4), 928-945. doi: 10.1007/s11469-017-9765 8

Lovibond, P. F., \& Lovibond, S. H. (1995). The structure of negative emotional states: Comparison of the Depression Anxiety Stress Scales (DASS) with the Beck Depression and Anxiety Inventories. Behaviour Research and Therapy, 33(3), 335-343. doi: 10.1016/0005-7967(94)00075-u

MacKinnon, D. P., Cheong, J., \& Pirlott, A. G. (2012). Statistical mediation analysis. In APA handbook of research methods in psychology, $\mathrm{Vol} 2$ : Research designs: Quantitative, qualitative, neuropsychological, and biological. (pp. 313-331). Washington, DC, US: American Psychological Association.

McCord, B., Rodebaugh, T. L., \& Levinson, C. A. (2014). Facebook: Social uses and anxiety.
Computers in Human Behavior, 34, 23-27. doi: 10.1016/j.chb.2014.01.020

Nejati, V., Zabihzadeh, A., Maleki, G., \& Tehranchi, A. (2012). Mind reading and mindfulness deficits in patients with major depression disorder. Procedia-Social and Behavioral Sciences, 32, 431437. doi: 10.1016/j.sbspro.2012.01.065

O'Keeffe, G. S., \& Clarke-Pearson, K. (2011). Clinical report-the impact of social media on children, adolescents, and families. Pediatrics, 27(4), peds.2011-0054. doi: 10.1542/peds.2011-0054

Özyesil, Z., Arslan, C., Kesici, Ş., \& Deniz, M. (2011). Adaptation of the mindful attention awareness scale into Turkish. Education and Science, 36(160), 224-235.

Pepping, C. A., O'Donovan, A., \& Davis, P. J. (2013). The positive effects of mindfulness on self-esteem. The Journal of Positive Psychology, 8(5), 376-386. doi: 10.1080/17439760.2013.807353

Podsakoff, P., MacKenzie, S., \& Podsakoff, N. (2003). Common method biases in behavioral research: A critical review of the literature and recommended remedies. Journal of Applied Psychology, 88(5), 879-903. doi: 10.1037/00219010.88.5.879

Preacher, K. J., \& Coffman, D. L. (2006). Computing power and minimum sample size for RMSEA. Retrieved from Available from http://quantpsy. org/.

Qiu, L., Lin, H., \& Leung, A. K.-y. (2013). Cultural differences and switching of in-group sharing behavior between an American (Facebook) and a Chinese (Renren) social networking site. Journal of Cross-Cultural Psychology, 44(1), 106-121. https://doi.org/10.1177/0022022111434597

Raes, F., Griffith, J. W., Van der Gucht, K., \& Williams, J. M. G. (2014). School-based prevention and reduction of depression in adolescents: $A$ cluster-randomized controlled trial of a mindfulness group program. Mindfulness, 5(5), 477486. doi: 10.1007/s12671-013-0202-1

Raftery, A. E. (1995). Bayesian model selection in social research. Sociological Methodology, 25, 111-164. doi: 10.2307/271063

Riley, B. (2014). Experiential avoidance mediates the association between thought suppression and mindfulness with problem gambling. Journal of Gambling Studies, 30(1), 163-171. doi: 10.1007/s10899-012-9342-9 
Roemer, L., Williston, S. K., \& Rollins, L. G. (2015). Mindfulness and emotion regulation. Current Opinion in Psychology, 3, 52-57. doi: 10.1016/j. copsyc.2015.02.006

Rosenberg, M. (1965). Society and the adolescent self-image: Princeton University Press.

Royuela-Colomer, E., \& Calvete, E. (2016). Mindfulness facets and depression in adolescents: Rumination as a mediator. Mindfulness, 7(5), 1092-1102. doi: 10.1007/s12671-016-0547-3

Russell, D. W., Kahn, J. H., Spoth, R., \& Altmaier, E. M. (1998). Analyzing data from experimental studies: A latent variable structural equation modeling approach. Journal of Counseling Psychology, 45(1), 18. doi: 10.1037/00220167.45.1.18

Ryan, R. M., \& Brown, K. W. (2003). Why we don't need self-esteem: On fundamental needs, contingent love, and mindfulness. Psychological Inquiry, 14(1), 71-76.

Ryan, T., Chester, A., Reece, J., \& Xenos, S. (2014). The uses and abuses of Facebook: A review of Facebook addiction. Journal of Behavioral Addictions, 3(3), 133-148. doi: 10.1556/ JBA.3.2014.016

Satici, S. A., \& Uysal, R. (2015). Well-being and problematic Facebook use. Computers in $\mathrm{Hu}$ man Behavior, 49, 185-190. doi: 10.1016/j. chb.2015.03.005

Satorra, A., \& Bentler, P. M. (1988). Scaling corrections for chi-square statistics in covariance structure analysis. ASA Proceedings of the Business and Economic Section, 1, 308-313.

Savci, M., \& Griffiths, M. D. (2019). The development of the Turkish Social Media Craving Scale (SMCS): A validation study. International Journal of Mental Health and Addiction. doi: 10.1007/ s11469-019-00062-9

Schermelleh-Engel, K., Moosbrugger, H., \& Müller, H. (2003). Evaluating the fit of structural equation models: Tests of significance and descriptive goodness-of-fit measures. Methods of Psychological Research Online, 8(2), 23-74.

Shapiro, S. L., Carlson, L. E., Astin, J. A., \& Freedman, B. (2006). Mechanisms of mindfulness. Journal of Clinical Psychology, 62(3), 373-386.

Shonin, E., Van Gordon, W., \& Griffiths, M. (2014). Mindfulness as a treatment for behavioural addiction. Journal of Addiction Research
\& Therapy, 5(1), e122. doi: 10.4172/21556105.1000e122

Silvia, P. J. (2002). Self-awareness and emotional intensity. Cognition and Emotion, 16(2), 195-216. doi: 10.1080/02699930143000310

Sriwilai, K., \& Charoensukmongkol, P. (2016). Face it, don't Facebook it: Impacts of social media addiction on mindfulness, coping strategies and the consequence on emotional exhaustion. Stress and Health, 32(4), 427-434. doi: 10.1002/ smi.2637

Şehidoğlu, Z. (2014). 15-17 yaş grubu ergenlerde bilinçli farkindalik düzeyi ile problemli internet kullanimi arasindaki ilişkinin incelenmesi [The study of the relationship between mindfulness and problematic internet usage of adolescents]. (Unpublished master thesis), Üsküdar University, İstanbul.

Tang, C. S. K., \& Koh, Y. Y. W. (2017). Online social networking addiction among college students in Singapore: Comorbidity with behavioral addiction and affective disorder. Asian Journal of Psychiatry, 25, 175-178. doi: 10.1016/j.ajp.2016.10.027

Tang, Y. Y., Ma, Y., Wang, J., Fan, Y., Feng, S., Lu, Q., . . . \& Fan, M. (2007). Short-term meditation training improves attention and self-regulation. Proceedings of the National Academy of Sciences, 104(43), 17152-17156. doi: 10.1073/ pnas.0707678104

Tekinarslan, E. (2008). Computer anxiety: A cross-cultural comparative study of Dutch and Turkish university students. Computers in Human Behavior, 24(4), 1572-1584. doi: 10.1016/j. chb.2007.05.011

Teper, R., Segal, Z. V., \& Inzlicht, M. (2013). Inside the mindful mind: How mindfulness enhances emotion regulation through improvements in executive control. Current Directions in Psychological Science, 22(6), 449-454. doi: 10.1177/0963721413495869

Thompson, B. L., \& Waltz, J. A. (2008). Mindfulness, self-esteem, and unconditional self-acceptance. Journal of Rational-Emotive \& Cognitive-Behavior Therapy, 26(2), 119-126. doi: 10.1007/ s10942-007-0059-0

Tice, D. M. (1993). The social motivations of people with low self-esteem. In R. Baumeister (Ed.), Self-Esteem: The puzzle of low self-regard (pp. 37-53). New York: Springer. 
Van der Oord, S., Bögels, S. M., \& Peijnenburg, D. (2012). The effectiveness of mindfulness training for children with ADHD and mindful parenting for their parents. Journal of Child and Family Studies, 21(1), 139-147.
We Are Social, \& Hootsuite. (2018). Digital in 2018 in Western Asia. https://www.slideshare.net/ wearesocial/digital-in-2018-in-western-asiapart-1-northwest-86865983 